\title{
The Learning Support Factors Affecting Learning Efficiency in the Bachelor of Public Administration Programme in Thailand.
}

\author{
Phathombut Keawsomnuk $^{1 *}$, Kamonwan Wanthanang ${ }^{2}$ and Muneeroh Yeedum ${ }^{3}$ \\ 1,2,3 Faculty of Humanities and social science, \\ Phranakhon Si Ayutthaya Rajabhat University, Thailand \\ ${ }^{*}$ Corresponding author
}

\begin{abstract}
.
This research analyses the learning support factor affecting learning efficiency in the Bachelor of Public Administration programme in Thailand. Factors include learning environments, learning media and learning efficiency. The study recruited205 Thai students in Ayutthaya province. The MIMIC model was applied. The findings show that learning efficiency of the Bachelor of Public Administration Programme is a perfect fit with empirical data. The provision of teaching efficiency for the public administration programme is learning through a variety of media.
\end{abstract}

Keywords: Learning Support, Learning Media, Learning Efficiency.

\section{Introduction}

Higher education needs to do more to prepare and produce high quality learners ready for the labour market. In this technological era, educators use digital resources to improve learning approaches and to support the learner, preparing them to become high-quality employees ready for the labour market. Companies require high-quality persons; therefore, it is the responsibility of the Thai government to develop worldclass higher education.

In 2014, the Thailand education ministry used an internal quality assurance system for universities. The internal quality assurance system (IQA) is divided into six parts, 1) monitoring, 2) graduates, 3) students, 4) teachers, 5) curriculum and 6) learning support. Within administering the curriculum, there is the important factor of learning support, which consists of the environments and facilities. That is, the classrooms, laboratories, research laboratories, teaching and learning facilities, libraries, information technology services, computers and $\mathrm{Wi}-\mathrm{Fi}$, that encourages students to learn with effectively and efficiently. These factors influence the students' ability to meet the learning standards required by the national higher education qualifications. Both the students and teachers need to be satisfied with the learning support provided. 


\section{BEHAVIORAL \& SOCIAL SCIENCES}

Learning support is a learning environment and the information technology provided by the local university. This study focused on Ayutthaya province, which is near Thailand's capital city, Bangkok. Therefore, it is appropriate to analyse the factors that influence the learning efficiency of students in the university, the results of which can be a guideline to improve the IQA within the university.

\section{Research Questions}

2.1 What is the relationship between the learning environment, information technology and learning efficiency?

2.2 What effect does the learning environment and information technology have upon learning efficiency in the Bachelor of Public Administration Programme at the university in Ayutthaya province?

Based on the research question and a review of the literature the following hypothesis model was constructed.

Figure 1. The hypothesis model.

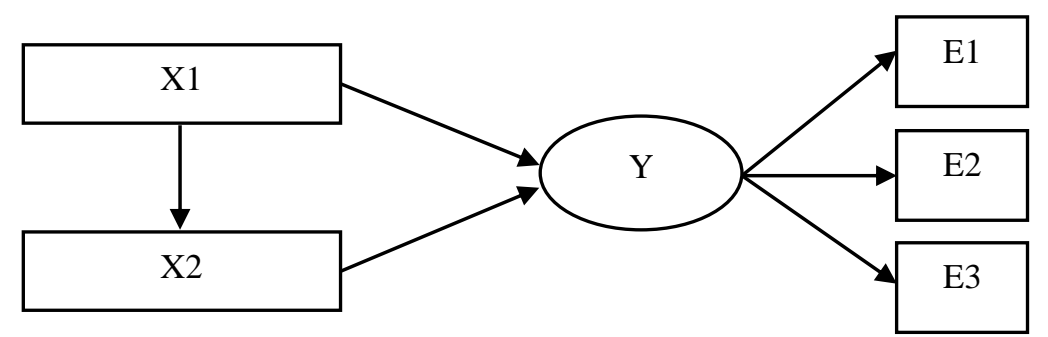

$\begin{array}{lll}\text { X1 } & \text { represents } & \text { Learning Environment } \\ \text { X2 } & \text { represents } & \text { Information Technology } \\ \text { Y } & \text { represents } & \text { Learning Efficiency } \\ \text { E1 } & \text { represents } & \text { Knowledge of students } \\ \text { E2 } & \text { represents } & \text { Skills of students } \\ \text { E3 } & \text { represents } & \text { Behaviour of students }\end{array}$




\section{BEHAVIORAL \& SOCIAL SCIENCES}

\section{Methodology}

This study used the quantitative methodology to collect data from 205 Thai students enrolled in a Bachelor of Public Administration Programme in Ayutthaya province. The reliability of Likert-scale score found that at 0.90 as well as it was an excellent questionnaire (George \& Mallery, 2010:231). The data was collected online using Google forms. The statistical analysis of data used the MIMIC technical model.

\section{Finding}

The result was divided into three parts.

\subsection{Basic information of respondent.}

Table 1. Overview respondents.

\begin{tabular}{|c|c|c|}
\hline Data & Frequency & Percentage \\
\hline Gender & & \\
\hline Male & 75 & 36.6 \\
\hline Female & 130 & 63.4 \\
\hline Total & 205 & 100.0 \\
\hline Class of position & & \\
\hline Year 1 & 64 & 31.2 \\
\hline Year 2 & 52 & 25.4 \\
\hline Year 3 & 64 & 31.2 \\
\hline Year 4 & 25 & 12.2 \\
\hline Total & 205 & 100.0 \\
\hline
\end{tabular}

The finding shows that the majority of the respondents were female, and were most likely to be in either their first or third year of university

\subsection{What is the relationship between the learning environment, information technology and learning efficiency?}

Table 2. The relationship between the learning environment, information technology and learning efficiency.

\begin{tabular}{|l|c|c|c|}
\hline \multicolumn{1}{|c|}{ Variable } & $\begin{array}{c}\text { Learning } \\
\text { environment }\end{array}$ & $\begin{array}{c}\text { Information } \\
\text { technology }\end{array}$ & Learning efficiency \\
\hline Learning environment & 1 & $.613^{* *}$ & $.520^{* *}$ \\
\hline Information technology & $.613^{* *}$ & 1 & $.537^{* *}$ \\
\hline Learning efficiency & $.520^{* *}$ & $.537^{* *}$ & 1 \\
\hline
\end{tabular}

\footnotetext{
. Significant at the 0.01
}

The results presented in Table 2 indicate that the relationship between variables ranged between 0.520 and 0.613 . It is a neutral relationship. 


\section{BEHAVIORAL \& SOCIAL SCIENCES}

4.3 What effect does the learning environment and information technology have upon learning efficiency in the Bachelor of Public Administration Programme of the university in Ayutthaya province?

Figure 2. MIMIC model of the Learning Support Factor Affecting Learning Efficiency in the Bachelor of Public Administration Programme.

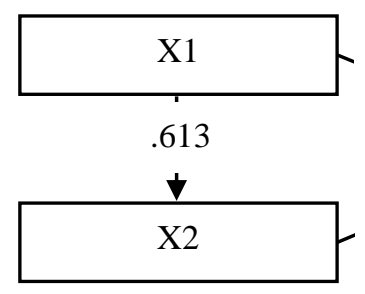

.357

.432

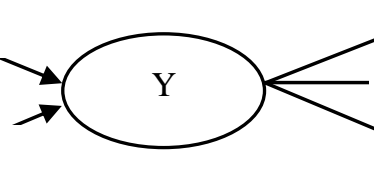

806

.768

538

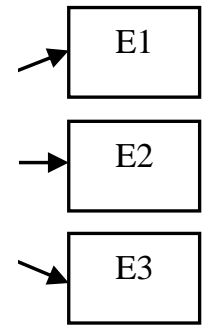

Chi-Square $=0.94$, Chi-Square $/ d f=0.31, d f=3, p$-value $=0.81$, $R M S E A=0.00, C F I=1.00, T L I=1.00, S R M R=0.05$

Table 3. Fit index of Structure model.

\begin{tabular}{|c|c|c|c|c|c|c|}
\hline Indexes & $\mathbf{X}^{\mathbf{2}}$ & $\mathbf{X}^{2} / \mathbf{d f}$ & RMSEA & CFI & TLI & SRMR \\
\hline Acceptable & $>0.5$ & $<2$ & $<0.05$ & $>0.95$ & $>0.95$ & $<0.10$ \\
\hline Calculated & 0.81 & 0.31 & 0.00 & 1.00 & 1.00 & 0.05 \\
\hline Result & Fit & Fit & Fit & Fit & Fit & Fit \\
\hline
\end{tabular}

Table 4. The direct effect and indirect effect.

\begin{tabular}{|l|c|c|c|c|c|c|}
\hline \multirow{2}{*}{ Variable } & \multicolumn{2}{c|}{ Information Technology } & \multicolumn{3}{c|}{ Learning Efficiency } \\
\cline { 2 - 7 } & DE & IE & TE & DE & IE & TE \\
\hline Learning Environment & 0.613 & - & 0.613 & 0.357 & 0.265 & 0.622 \\
\hline Information Technology & - & - & - & 0.432 & - & 0.432 \\
\hline
\end{tabular}

DE mean Direct Effect, IE mean Indirect Effect, TE mean Total Effect 
The research results can be summarised in a model where the factors relate to the learning efficiency of the Bachelor of Public Administration Programme as follows:

Figure 3. The final model.

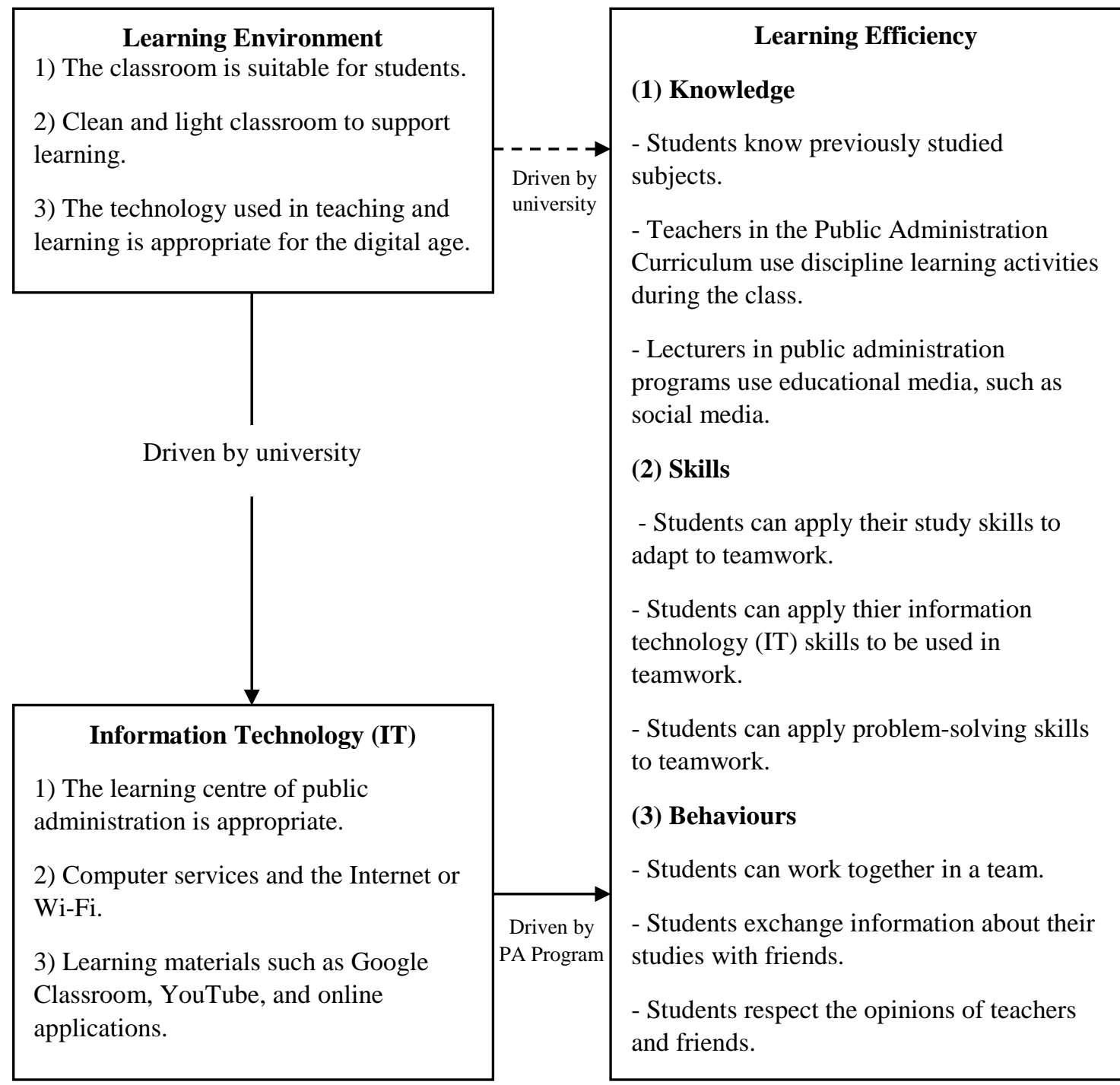

Weak Effect

$\overrightarrow{\text { Strong Effect }}$ 


\section{Discussion and Conclusion}

Based on the research finding, information support factors have a significant influence upon student learning. The support provided by the Public Administration Department has a greater effect upon the efficiency of students' learning than the supporting environmental factors in the university. The analysis of the confirmatory factors of learners' learning efficiency found that the importance of the knowledge and skills factors to be high. Which can be discussed that students in public administration programme, when promoting learning through information media can improve learning efficiency. According to Sidana and Sarin (2017:747), information and communication technology has a high level of efficiency in automation, optimisation, knowledge sharing and easy access to information. It is very useful for developing educational skills; and may significantly increase academic performance compared to not using technology (Mohammed and Abdulghani, 2017:84). According to a survey conducted by Kemp in January 2020, the number of Thai people accessing the internet in Thailand has risen from over 52 million to nearly 69 million. Developing the online education system is the new hope for university teachers. The benefits of information technology for higher education are that it promotes knowledge, skills and behaviour that support smart humans entering the global labour market.

In summary, this research confirms that students will improve their learning efficiency by using technological media. The Thai government should support learning efficiency for all students by providing information technology at all levels of the education system. This will improve students' educational achievement and develop their skills needed for working with colleagues in the future.

\section{References}

[1] George, Darren, \& Mallery, Paul. (2010). SPSS for Windows step by step : a simple guide and reference, 17.0 update (10th ed.). Boston: Allyn \& Bacon.

[2] Kemp, S. (2020). Digital 2020: Thailand - DataReportal - Global Digital Insights. Retrieved May 7, 2020, from https://datareportal.com/reports/digital-2020-thailand

[3] Mohammed, T., and Abdulghani, A. (2017). Impact of students' use of technology on their learning achievements in physiology courses at the University of Dammam. Journal of Taibah University Medical Sciences, Volume 12, Issue 1, February 2017, Pages 82-85.

[4] Sidana, N., \& Sarin, V. (2017). Revolutionary Impact of Information Technology on Education. International Journal of Economic Research. 14. 741-748. 